Max-Planck-Institut für demografische Forschung

Max Planck Institute for Demographic Research

Doberaner Strasse $114 \cdot$ D-18057 Rostock $\cdot$ GERMANY

Tel +49 (0) 3812081 - 0; Fax +49 (0) 3812081 - 202;

http://www.demogr.mpg.de

MPIDR WORKING PAPER WP 2002-024

JUNE 2002

\title{
Fertility in times \\ of discontinuous societal change: the case of Central and Eastern Europe
}

Dimiter Philipov (philipov@demogr.mpg.de)

This working paper has been approved for release by: Vladimir M. Shkolnikov (shkolnikov@demogr.mpg.de), Head of the Laboratory for Demographic Data.

(C) Copyright is held by the authors.

Working papers of the Max Planck Institute for Demographic Research receive only limited review. Views or opinions expressed in working papers are attributable to the authors and do not necessarily reflect those of the Institute. 
Fertility in times of discontinuous societal change: the case of Central and Eastern Europe

\author{
Dimiter Philipov \\ Max-Planck Institute for Demographic Research \\ Rostock, Germany \\ philipov@demogr.mpg.de
}




\section{Introduction}

The socialist regime in the Central and Eastern European countries is gone for more than 10 years, a period known as one of transition from a planned and totalitarian to a market and democratic society. The planned society collapsed by itself at the very start, leaving place for the gradual emergence of a market-based social order. The transition thus achieved the form of discontinuity, or hiatus: a period that lasts since the sudden break from the past and till the steady establishment of a market-oriented democratic social order. Discontinuity encompassed drastic changes in all spheres of life.

Reorganization of state institutions during this period caused its weakening. Replacement of old laws with new ones caused a weakening in the legal system. The economy was restructured on the basis of rising private property and free market relations. Some people came to know impoverishment, others enrichment. At the beginning of the transition people hoped that such a transition would last a couple of years. It took longer. Nowadays some countries are close to its end while others have still a long way to go.

The entire change in life did not overpass demographic events. Marriages and births decreased and were postponed, the share of non-marital unions and extra-marital births increased. Some of the demographic changes, such as the abrupt fall in fertility, were unprecedented in the history of mankind in peaceful times. The total fertility rate (TFR) decreased to app. 1 and the total first-marriage rate (TFMR) went down below 0.5 in some countries from the region. Analogous drifts were observed in all countries in the region. The populations in the region experience similar fertility and union-formation trends during times of political, social and economic divergence.

Demographers explain these tendencies in diverse ways. Some find the economic difficulties of the transition as the primary cause for the new demographic trends. Indeed, the pervasive economic decline has brought about a considerable increase in the costs of children. Others argue that the drop in fertility is basically the result of long-standing ideational changes that have started developing before the start of the transition. The latter has only contributed to their rise at the surface and accelerated their intensity and diffusion. Both approaches give a valuable insight to the understanding of recent fertility changes in the countries from the region.

This paper argues that the two grand approaches do not incorporate in full the quintessence of the transition, describing it in too general terms. It presents a broad theoretical framework that fits the specifics in the economic and ideational development in the region.

The transition as a discontinuity threatens security of jobs and income and hence supports the rise in economic hardship and impoverishment. It affects norms, values, preferences, attitudes, and behavior. The break of norms and values unfolds social anomie. Disorientation and uncertainty increase in societies where normlessness prevails. Affected people may decide to postpone and even reject crucial and irreversible life events, such as marriage or birth of a child. Hence discontinuity, along with other factors, causes a fall in fertility.

While rise in personal disorientation and economic hardship cause a decrease in fertility, the question remains open as to why do people have children under significantly worsened conditions of life. People react to disorderliness, anomie, deinstitutionalization 
and the consequent rise in uncertainty in diverse ways. Some may remain passive, while others undertake diverse actions, or coping strategies. Persons who manage to develop successful coping strategies may lower their burden of uncertainty and hence be less willing to postpone or reject a birth. Under the reign of disorderliness people rely mostly on their social networks either for achieving successful coping strategies or just for making ends meet. One can get from a friend or a relative a money loan or some key information for finding a job. The more the social resources one is able to mobilize out of the social network, the higher the chances for coping with the difficult living situation. Mobilization of social resources is characteristic of the individual's social capital. Social capital helps thus survive, and for some prosper, in times of social anomie and discontinuity in social order. These people are more likely to decide positively on a nonreversible event such as a birth of a child.

The lack of data is a significant obstacle for an in-depth comparative research and assessment of any theoretical approach to the recent fertility changes in the region. This paper relies on vital statistics data and on supportive indication derived by survey data for Bulgaria and Russia. The latter are used to test one part of the presented theoretical framework, namely the significance of social capital.

The first section introduces the reader to the turbulent social and economic development in the region. The next one describes the drift in fertility observed in the Central and Eastern European (CEE) countries during the 90s. The third and fourth sections discuss the two grand explanatory approaches to these drifts and reveal the inadequacy of their conventional usage for explaining the fertility changes in the region. The fifth section emphasizes discontinuity as an essential characteristic of the transition, and the disorderliness and anomie in society it has caused. The sixth section discusses the way disorderliness and anomie link to fertility, and the significance of social capital in the formulation of demographic decisions. Section 7 supports the significance of social capital using results from a logistic regression with individual-level data for Bulgaria and Russia.

The countries of interest are grouped in four regions. They are (a) Central European countries: The Czech Republic (Czechia), Hungary, Poland, The Slovak Republic (Slovakia), and Slovenia; (b) Baltic countries: Estonia, Latvia, and Lithuania; (c) South-Eastern European countries: Bulgaria, the Former Yugoslav Republic of Macedonia (FYROM), Romania; (d) CIS countries (Commonwealth of Independent States): Belarus, Moldova, The Russian Federation (Russia), and the Ukraine.

The discussion excludes other ex-Yugoslav countries, Albania and the TransCaucasian countries where the social aftermath of the transition may have affected in a specific way the demographic trends. The ex-German Democratic Republic is also excluded, although the discussion here could be relevant to the new provinces of today's Germany.

The time period of interest is the last decade of the Twentieth Century.

\section{The context of the transition}

The totalitarian regimes collapsed in the Central European ex-socialist countries in the end of 1989, and the USSR disintegrated in the end of 1991. These are the starting years of the transition. The aim of the transition is common: a democratic society of a 
Western European type. The description given below refers more or less to all countries in the region. The major differences among the countries are in pace, timing, and intensity of these historical events.

\subsection{Political and economic aspects of the transition}

Politically, the transition started when a multi-party ruling system replaced virtually within days the totalitarian regime. The civil society began its gradual revival. The ex-communist parties retained legally the power, or returned to power for some periods during the decade. The transition in the legal system started with significant constitutional changes, or adoption of new constitutions, with the purpose to abolish the legal power of the communist ideology. The path towards a democratic society required replacement of numerous laws and acts with new ones. The speedy legal changes called for repeated amendments in the new laws. Thus the legal system was, and is, in a process of continuous renovation.

The transition in the economic system took the course from a planned-oriented to a free market economy. The reforms began right at the start with liberalization of prices, trade, markets and market entry. The private sector marked a significant rise, due by and large to privatization and reconstitution of old property in some of the countries. The collapse of Comecon (common market of the socialist countries) and the USSR demolished traditional secure markets. Enterprises re-oriented their trade, with the preference being towards the more developed countries in Western Europe. The financial markets revived with the birth of numerous banks. Stock markets revived. Currency convertibility was eased. Liberalization was shortly followed by macroeconomic stabilization. The latter had to fight rising inflation through fiscal, monetary, and wage policies, although with diverse success.

The reforms started at a time when the economies of all CEE countries were near collapse. The initial conditions were substantially different: some countries inherited significant foreign debts, and/or had their export oriented exclusively towards Comecon or the ex-USSR. Nevertheless, all countries experienced an economic shock with the start of the reforms. Thus in most of the countries the GDP decreased by at least 10 points in only 1-2 years. The further path of the change in the GDP was diverse. In some countries, notably the Czech Republic, Hungary, Poland, and Slovenia, a gradual recovery began immediately after the initial shock. Towards the end of the decade the 1989 level was nearly recovered or even surpassed (table 1). In the Baltic countries the recovery started around the middle of the decade, while in most of the other countries it started later or the recession is still going on. The rate of change in the GDP corresponds to the pace, timing, and intensity of the reforms. The better-off countries initiated rapid adjustment reforms, often close to laissez-faire, while others pertained to sustained change, or gradual economic adjustment.

The GDP per capita allows for a different type of comparisons that are of importance to the further discussion in this article. Table 1 shows that its level drops down with each subsequent geographical region. The GDP per capita increased significantly in the Baltic countries during the last years of the decade. They were shortening the distance to the leading group of countries in Central Europe, while at the same time getting considerably better than the countries from the third and particularly from the fourth group, with which they were in one and the same state (USSR). 
Table 1: GDP, Students and Unemployment

\begin{tabular}{|l|cc|cc|cc|}
\hline & $\begin{array}{c}\text { Real } \\
\text { GDP in } \\
1999\end{array}$ & $\begin{array}{c}\text { Per } \\
\text { capita in } \\
\text { US\$ }\end{array}$ & \multicolumn{2}{|c|}{$\begin{array}{c}\text { Number of students } \\
\text { per 10,000 } \\
\text { inhabitants }\end{array}$} & \multicolumn{2}{|c|}{$\begin{array}{c}\text { Unemployment } \\
\left(^{*}\right)\end{array}$} \\
& $1989=$ & 1999 & 1990 & 1996 & 1990 & 1999 \\
\hline Czech Rep. & 95 & 5189 & 115 & 201 & 0.8 & 9.4 \\
Hungary & 99 & 4853 & 99 & 190 & 1.9 & 9.9 \\
Poland & 122 & 3987 & 143 & 186 & 6.3 & 13 \\
Slovakia & 100 & 3650 & - & 190 & $10.4^{(1)}$ & 19.2 \\
Slovenia & 109 & 10020 & 175 & 266 & $4.7^{(2)}$ & 7.4 \\
\hline Estonia & 77 & 3564 & 175 & 296 & $6.6^{(2)}$ & 12.4 \\
Latvia & 60 & 2582 & 171 & 225 & $3.9^{(1)}$ & 13.5 \\
Lithuania & 62 & 2880 & 247 & 225 & $0.3^{(3)}$ & 14.1 \\
\hline Bulgaria & 67 & 1513 & 216 & 311 & 1.5 & 16 \\
FYROM & 74 & 1701 & 140 & 156 & $19.2^{(3)}$ & 32.4 \\
Romania & 76 & 1517 & 83 & 182 & $8.2^{(1)}$ & 11.8 \\
\hline Belarus & 80 & 777 & 327 & 317 & 0 & 2.1 \\
Moldova & 31 & 271 & 240 & 214 & - & 2 \\
Russia & 57 & 1249 & 344 & 301 & 0 & 11.7 \\
Ukraine & 36 & 620 & 318 & 300 & 0 & 4.3 \\
\hline
\end{tabular}

(*) registered, in percent of the labor force;

(1) 1992; (2) 1993; (3) 1991;

Sources:

GDP and unemployment: E.B.R.D. (1997, 2000).

University students: UNESCO.

\subsection{Social aspects of the transition}

The social aspects of the transition relate mostly to changes in educational enrolment, social stratification and income inequality, as well as rise in impoverishment and unemployment.

Education. The liberalization of the market rose the need of new professions and occupations, such as business management, accounting and finances, banking. Demand for labor specialized in these fields was bare during the times of planned economy. Hence the supply side of this labor market was poor at the start of the transition. This gave impetus to the expansion of proper education. Private schools and universities appeared. Thus market-driven education replaced the planned one. Education increased extensively: among an increasing number of people, and intensively: towards higher levels, were at hand.

Table 1 outlines the rapid growth of the number of university-level students in the CEE countries with the exception of the CIS countries where it was high at the start of the transition. Other sources also support the rapid increase in the share of students. In U.N.E.C.E. (2000, page 199) it is noted that the proportions of 18-22 year old women in Hungary, Poland, Bulgaria, and Romania, attending higher education institutions have doubled in 1997 relative to 1989 . Fratczak (2000, p.32) notes that the enrolment ratio in universities for persons aged 18-24 increased from 6\% in 1990 to 25\% in 1996. This level is considerably lower than those observed in Western Europe. Hence the expansion of education is likely to continue. 
The rise in educational expenses forced some students to combine work with study, possibly breaking the study for some time. Such effects contribute to a postponement of education.

Unemployment. Unemployment did not exist, at least officially, during the totalitarian regime. Even frictional unemployment was not registered. Table 1 indicates a considerable rise in unemployment during the 10-year period. Data not presented here reveal well-known patterns of higher unemployment among sub-groups of the population, such as women and young adults. Long-term unemployment and the associated high level of discouraged workers are typical for all the CEE countries.

Impoverishment. It is another new aspect of social life in the CEE countries. Impoverishment spread quickly and reached considerable levels in some countries. Table 2 presents the percentage of the population below a poverty line of 4 US Dollars per capita per day. Like unemployment, poverty starts from very low and rises to very high levels.

Table 2: Per cent of population in poverty (per cent earning less than 4 US Dollars per capita per day)

\begin{tabular}{|c|c|c|}
\hline & $1987-88$ & $1993-95$ \\
\hline Hungary & 1 & 7 \\
Poland & 6 & 10 \\
\hline Estonia & 1 & 34 \\
\hline Romania & 6 & 48 \\
\hline Belarus & 1 & 14 \\
Russia & 2 & 39 \\
Ukraine & 2 & 26 \\
\hline
\end{tabular}

Source: Milanovic (1998)

Income inequality. Inequality existed during the totalitarian regime at least because of the existing of privileged nomenclatura, but its level should have been low because of the equalized payment of diverse labor. The free market regime brought about the spread of both impoverishment and enrichment. The Gini coefficient in the Czech Republic for example rose from 21.2 in 1991 to 25.9 in 1997; in Hungary from 30.5 in 1993 to 34.8 in 1997; in Romania from 20.4 in 1991 to 42.2 in 1997.

Declining effectiveness of family and other policies. U.N.E.C.E. (2000) provides a concise discussion on family policies in the CEE countries. It is pointed that at the start of the transition nearly all countries had well designed and affluent family policies with effective instruments, such as maternity and childcare leaves, compensation for income during maternity leave, child allowances. During the transition period parental leaves have been preserved, although pregnancy arose as an obstacle to finding work. Payments decreased, in some countries considerably, due to periodic and high inflation. The number of kindergartens decreased, partially due to privatization of housing stock

The transition had its specific trajectory in each country, but generalizations for groups of countries are possible where overall political, economic, and social changes are considered. In the countries from the Central European region the initial economic recession was soon followed by an economic recovery, and the political system is far from the one of the ex-socialist type. The overall development in the Baltic countries speeded up towards the middle of the 90-s and near the end of the decade they were 
catching up with the above group. The countries from group (c), South-Eastern Europe have a longer way to go where the economic and the political systems are considered, although in social aspects they are close to the Baltic countries. Finally, the CIS countries are further away from free markets but unemployment is not as high in these countries.

Before the transition the CEE countries formed a relatively uniform region where political, social, and economic aspects are considered. The transition ended this uniformity; it represented a period of divergence in this part of Europe.

\section{Changes in fertility: a brief description}

This section provides a brief description of fertility changes around the start and during the transition period. (See also Monnier 1996, Monnier and Rychtaříková 1992, U.N.E.C.E. 1999 and 2000. Kucera et al. 2000, as well as the FFS CRS-s ${ }^{1}$ offer comparative studies for countries in the region).

\section{Fertility before the start of the transition}

Before the start of the transition fertility changed primarily as a result of the pronatal population policies adopted in most of the CEE countries. The latter alleviated fluctuations of the TFR close to replacement level. During the 80s (table 4 gives the values for 1980 and 1989) the TFR was slightly above replacement level in some countries (notably in Poland, Romania, nowadays Yugoslavia), slightly below in others (like Bulgaria, Czech Republic, Hungary), and around replacement in nearly all the remaining countries. Slovenia and Hungary are significant exceptions. In Slovenia the drop in fertility was initiated considerably earlier than in any other CEE country, and the trend developed smoothly, like in the non-CEE European countries.

Table 4: Total fertility rate (TFR)

\begin{tabular}{|l|rrrrrrrrrrrrrr|r|}
\hline & $\mathbf{1 9 8 0}$ & $\mathbf{1 9 8 9}$ & $\mathbf{1 9 9 0}$ & $\mathbf{1 9 9 1}$ & $\mathbf{1 9 9 2}$ & $\mathbf{1 9 9 3}$ & $\mathbf{1 9 9 4}$ & $\mathbf{1 9 9 5}$ & $\mathbf{1 9 9 6}$ & $\mathbf{1 9 9 7}$ & $\mathbf{1 9 9 8}$ & $\mathbf{1 9 9 9}$ \\
\hline Czech R. & 2.10 & 1.88 & 1.9 & 1.86 & 1.72 & 1.67 & 1.44 & 1.28 & 1.18 & 1.17 & 1.16 & 1.13 \\
Hungary & 1.91 & 1.82 & 1.87 & 1.88 & 1.78 & 1.69 & 1.65 & 1.58 & 1.46 & 1.38 & 1.33 & 1.29 \\
Poland & 2.26 & 2.08 & 2.04 & 2.05 & 1.93 & 1.85 & 1.8 & 1.61 & 1.58 & 1.51 & 1.43 & 1.37 \\
Slovak R. & 2.31 & 2.08 & 2.09 & 2.05 & 1.93 & 1.87 & 1.67 & 1.52 & 1.47 & 1.43 & 1.38 & 1.33 \\
Slovenia & 2.10 & 1.52 & 1.46 & 1.42 & 1.33 & 1.33 & 1.32 & 1.29 & 1.28 & 1.25 & 1.23 & 1.21 \\
\hline Estonia & 2.02 & 2.21 & 2.05 & 1.79 & 1.69 & 1.45 & 1.37 & 1.32 & 1.3 & 1.24 & 1.21 & 1.24 \\
Latvia & 1.90 & 2.05 & 2.02 & 1.86 & 1.73 & 1.51 & 1.39 & 1.25 & 1.16 & 1.11 & 1.09 & 1.16 \\
Lithuania & 1.99 & 1.98 & 2 & 1.97 & 1.89 & 1.69 & 1.52 & 1.49 & 1.42 & 1.39 & 1.36 & 1.35 \\
\hline Bulgaria & 2.05 & 1.87 & 1.78 & 1.66 & 1.55 & 1.46 & 1.37 & 1.23 & 1.23 & 1.09 & 1.11 & 1.23 \\
Romania & 2.43 & 2.2 & 1.84 & 1.58 & 1.5 & 1.44 & 1.41 & 1.34 & 1.3 & 1.32 & 1.32 & 1.3 \\
FYROM & 2.47 & - & 2.06 & - & - & - & - & 2.13 & - & 1.93 & 1.9 & 1.76 \\
\hline Belarus & 2.00 & 2.01 & 1.91 & 1.8 & 1.75 & 1.61 & 1.57 & 1.39 & 1.32 & 1.23 & 1.27 & 1.29 \\
Moldova & 2.39 & 2.46 & 2.39 & 2.26 & 2.21 & 2.1 & 1.95 & 1.76 & 1.6 & 1.67 & - & - \\
Russia & 1.86 & 2.01 & 1.89 & 1.73 & 1.55 & 1.39 & 1.4 & 1.34 & 1.28 & 1.23 & 1.24 & 1.17 \\
Ukraine & 1.95 & 1.92 & 1.89 & 1.81 & 1.72 & 1.55 & 1.5 & 1.4 & 1.38 & 1.36 & 1.19 & - \\
\hline
\end{tabular}

Source: Recent Demographic Development in Europe, 2001. 
The period first-order TFR (denoted by TFR1) was close to unity in all the countries from the region, with the exception of the GDR and Hungary, where it dropped towards 1989 slightly below 0.8 . TFR1 levels as high as these indicate a nearly universal birth of a first child. This pattern was observed over time as well. The second-order TFR2 was high as well: its values were above 0.7 . These high levels indicated the prevalence of a two-child family model. Order-specific completed cohort fertility supports the periodbased observations, indicating even closer values to 1 for the cohort TFR1 (Council of Europe, 2001).

The mean age at birth of the first child was very low in all the countries. It changed only little during the years before 1990 (table 5). Such low values indicate the prevalence of a pattern of early childbearing over the region. The age-specific fertility rates (not shown here) demonstrate that the age schedules of the birth of first child were narrow. The data also reveal that fertility stopped at an early age: by age 30 around $90 \%$ of all births have already taken place.

Table 5: Mean age of mothers at birth of first child

\begin{tabular}{|l|cccccccccccc|}
\hline & $\mathbf{1 9 8 0}$ & $\mathbf{1 9 8 9}$ & $\mathbf{1 9 9 0}$ & $\mathbf{1 9 9 1}$ & $\mathbf{1 9 9 2}$ & $\mathbf{1 9 9 3}$ & $\mathbf{1 9 9 4}$ & $\mathbf{1 9 9 5}$ & $\mathbf{1 9 9 6}$ & $\mathbf{1 9 9 7}$ & $\mathbf{1 9 9 8}$ & $\mathbf{1 9 9 9}$ \\
\hline Czech R. & 22.4 & 22.5 & 22.5 & 22.4 & 22.5 & 22.6 & 22.9 & 23.3 & 23.7 & 24.0 & 24.4 & 24.6 \\
Hungary & 22.4 & 23.1 & 23.1 & 23.2 & 23.3 & 23.4 & 23.6 & 23.8 & 24.1 & 24.3 & 24.5 & 24.8 \\
Poland & 23.4 & 23.3 & 23.3 & 23.3 & 23.4 & 23.5 & 23.6 & 23.8 & 23.9 & 24.1 & 24.2 & 24.4 \\
Slovak R. & 22.7 & 22.6 & 22.6 & 22.5 & 22.6 & 22.7 & 22.8 & 23.3 & 23.2 & 23.4 & 23.6 & 23.8 \\
Slovenia & 22.9 & 23.5 & 23.7 & 23.1 & 24.1 & 24.5 & 24.6 & 24.9 & 25.2 & 25.5 & 25.8 & 26.1 \\
\hline Estonia & 23.2 & 23.0 & 22.9 & 22.7 & 22.7 & 22.7 & 22.8 & 23.0 & 23.2 & 23.4 & 23.6 & 23.8 \\
Latvia & 22.9 & 22.9 & 23.0 & 22.9 & 22.8 & 22.9 & 23.3 & 23.3 & 23.5 & 23.8 & 24.0 & 24.2 \\
Lithuania & 23.8 & 23.4 & 23.2 & 23.1 & 23.1 & 23.2 & 23.0 & 23.1 & 23.2 & 23.3 & 23.6 & 23.7 \\
\hline Bulgaria & 21.9 & 22.1 & 22.2 & 22.0 & 21.9 & 22.0 & 22.2 & 22.4 & 22.6 & 22.8 & 22.9 & 23.0 \\
Romania & 22.4 & 22.6 & 22.6 & 22.6 & 22.6 & 22.5 & 22.6 & 23.0 & 23.1 & 23.3 & 23.4 & 23.5 \\
FYROM & 23.2 & 23.4 & 23.4 & 23.5 & 23.5 & 23.5 & 23.6 & 23.7 & 23.8 & 23.8 & 24.1 & 24.1 \\
\hline Belarus & - & 22.8 & 22.6 & 22.5 & 22.5 & 22.4 & 22.4 & 22.4 & 22.5 & 22.5 & 22.6 & 23.2 \\
Russia & 23.0 & 22.8 & 22.6 & 22.6 & 22.6 & 22.6 & 22.5 & 22.7 & 22.9 & 23.0 & - & - \\
\hline
\end{tabular}

Before the start of the transition the CEE countries were more divergent in the level of extra-marital births than in any other fertility-related demographic trend. This level was higher in the Baltic countries, Russia, the GDR and ex-Yugoslavia than elsewhere. Towards the end of the 80-s the share of these births marked a slight increase.

Birth control was dominated by the usage of traditional methods. Supply of modern methods was limited, particularly in countries with a pronatal policy, but less so in the Central European countries.

This short outline suggests the domination of a fertility pattern characterized with:

- nearly universal birth of a first child;

- early start of childbearing clustered into a narrow age interval.

Slovenia, Croatia, and partially other ex-Yugoslav countries are important exceptions of all or at least some of these patterns. The populations of these countries were on the start towards demographic patterns observed in Western Europe since the beginning of the 80s. The difference can be associated to their exceptional for the region political and economic status yet before the start of the transition. 


\section{Fertility during the transition}

The TFR (table 4) indicates a swift and huge drop in the level of fertility during the 90s. In some countries the decrease was slower during the first few years of the transition (Czech and Slovak Republic, Hungary, Poland). In nearly all other countries it was steepest namely during these first years. In the ex-USSR countries the decrease began before the collapse of the state, with the exception of Lithuania where it started with the achieved independence. In Slovenia, as well as in the other ex-Yugoslav republics, the decrease was not as steep because the TFR was already low around 1989.

During the 90s the mean age of childbearing marked a considerable increase in all countries. In order to avoid statistical problems connected to changes in the weights of different birth orders, the discussion focuses on women's mean age of birth of first child (table 5). It marked a rapid rise in all countries, particularly notable in Czechia, Slovenia and Hungary. Such a steep rise in the mean age of mothers at birth of the first child indicates a break from the recent behavior of a birth at a young age. The 90 -s witnessed a considerable postponement of births.

It is well known in demography that postponement of births distorts the period TFR by introducing a component known as a tempo effect. Bongaarts and Feeney (1998) suggested a formula that allows the adjustment of the TFR for this distortion, by decomposing the observed TFR into tempo and quantum components. Philipov and Kohler (2001) used it for the analysis of tempo and quantum fertility change in Bulgaria, the Czech Republic, Hungary, Poland, and Russia. Their results, along with similar estimations for Slovakia and Lithuania, reveal that the fall in fertility during the 90-s was due to significant tempo and quantum effects. The adjusted TFR was close to the observed one at the start of the transition, while towards the end of the 90-s it was around 1.6. For example in 1999 it was nearly 1.6 in Bulgaria and Lithuania and 1.7 in Hungary, while the observed TFR were correspondingly $1.23,1.35$ and $1.28 .^{2}$ Therefore the level of fertility in the end of the decade, as measured with the tempo-free TFR, was considerably lower than in the beginning of the decade, although not as low as indicated by the observed TFR.

Similar inferences can be made where the adjustment of the TFR1 is considered. The adjusted TFR1 were higher than the observed ones but they were lower than around 0.9 . The latter can be conceived as a proxy to the minimal level that could be observed under the prevalence of universal childbearing. ${ }^{3}$ Therefore the end of the $90 \mathrm{~s}$ is a period of a spread of voluntary childlessness in many countries in Central and Eastern Europe, as far as the tempo-adjusted first-order TFR indicates. This is a break from a longstanding and stable reproductive norm. ${ }^{4}$

Extra-marital fertility marked a considerable increase during the decade of interest. In most of the countries its initial start from low levels led to unprecedented high levels (table 6). In some countries its rise began before the transition, but care should be taken for its interpretation because it could be an artifact of the population policy. In particular, lonely mothers were granted advantages, such as priority in housing supply and tax reduction. The data indicate that towards 1999 the traditional dominance of marital fertility is gone in many countries from the region. Rychtaříková (2000) notes that the relative rise in extra-marital fertility in the Czech Republic (number of babies per 100 live births) is the result of falling marital fertility. The relative rise can be explained by 
the presence of heterogeneity in the population: a certain sub-population group may traditionally have a high level of extra-marital fertility and have maintained it during the transition period with a relatively low decline in its fertility. Ethnic groups like the RomaGypsies that reside mainly in the South-Eastern European countries are an example. This consideration does not explain though the rise in extra-marital fertility in absolute terms.

A part of extra-marital fertility is contributed to extramarital unions. An indication of this share gives table 15 from the FFS SCR's (see note 1). The survey data indicate that less than half, some $30-45 \%$ of all extra-marital births were recorded to a non-marital partnership. Lithuania and Poland are exceptional in that this share is much lower, $12 \%$ and $13 \%$ correspondingly. The FFS data indicate also that there is an increase in the share of births in non-marital partnerships.

\section{Table 6: Extra-marital births in 1990 and 1999 (in percent to all live births)}

\begin{tabular}{|c|c|c|}
\hline & 1990 & 1999 \\
\hline Czech Rep. & 8.6 & 20.6 \\
Hungary & 13.1 & 28.0 \\
Poland & 6.2 & $11.6^{*}$ \\
Slovakia & 7.6 & 16.9 \\
Slovenia & 24.5 & 35.4 \\
\hline Estonia & 27.1 & 54.0 \\
Latvia & 16.9 & 39.1 \\
Lithuania & 7.0 & 19.8 \\
\hline Bulgaria & 12.4 & 35.1 \\
Romania & $17.0 * *$ & 24.1 \\
\hline Belarus & 8.5 & 17.8 \\
Russia & 14.6 & 27.9 \\
\hline \multicolumn{2}{|c|}{ * in 1998; ** in 1993 } \\
\hline \multicolumn{2}{|c|}{ Source: Council of Europe (2001). }
\end{tabular}

Another reason for the rise in extra-marital fertility is the inefficiency or nonpracticing of contraceptive behavior, particularly among teenagers. Early start of sexual life spread widely during the transition period while usage of modern contraceptives spread at lower rate. Teenage fertility increased tremendously in some countries, to rank them among the highest in Europe. A third reason for the rise in extra-marital fertility is the conception preceding the marriage; the couple may go into a legal marriage after the birth (see Vikat, 1994 for the high rate of births preceding marriage in Estonia).

Although scanty, the information shows that at least part of the extra-marital births is due to the rise of new preferences and tastes, and break from traditional norms and behavior.

The postponement of marriages and the increase of the share of single persons in reproductive age have their impact on the tempo and quantum of fertility as far as marriage is a prerequisite to fertility. One can see this link inversed, in that people do not marry because they do not want to have children. This topic needs additional research in the CEE countries.

Finally, one should consider the impact of emigration on the estimation of the fertility rates. During the decade many young people have left their countries, whether for studying or working abroad. The number of emigrants is unknown. In Bulgaria it is 
considered to be around 700,000 and this is app. $8 \%$ of the total population. Due to the lack of information these people are considered to be within the country and therefore are included in the denominators of the fertility rates. A simple simulated estimation (done by extracting 10,000 women from each age group in the age interval 18-28) shows that the observed TFR in Bulgaria in 1998 could have been 1.3 instead of the observed 1.1.

This paper will not discuss family planning issues. David (1999) provides a discussion related to countries in the region. I will just mark some facts. Many countries adopted legal changes related to family planing with the purpose to make it respond to a democratic society. Family planning organizations were initiated and developed. Modern contraceptives became available, although at high price for part of the population. Abortion rates decrease but are still high in comparison to western societies. It is worth noting that the 1993 legalization of abortions had no particular effect on fertility in Poland (Kulczycki, 1995).

The descriptive analysis presented here brings to essential inferences. Fertility trends during the transition differ entirely from those observed during the pre-transition period. The data support the break of norms that have prevailed during the previous decades:

- The traditional pattern of early and nearly universal motherhood is replaced by one of an increasing mean age of first birth and loss of universality of maternity.

- Extra-marital fertility increased.

The most striking inference is the speed of the changes. The new trends exploded and spread within a decade. Although the pace differed, towards the end of the decade the fertility trends converged, just like in the end of the 80-s.

\section{Basic approaches to the explanations of fertility changes}

The sudden change in fertility behavior has been a topic of hot debates in the mass media as well as among scientists from countries in the region. The prevailing explanations can be broadly collected into two groups. One relates to the direct social and economic effect of the transition, while the other emphasizes ideational changes. I refer to these two approaches as to the economic one and the ideational one.

\section{(a) The economic approach}

This approach relates to the social and economic hardships experienced by large groups of the population in the countries from the region. The social and economic indicators in tables 1 to 3 and the measures of fertility are correlated, as can be seen without the application of any statistical analysis. This visual correlation is viewed as a causal relation, used by some scientists, politicians and mass media to assess the demographic situation as catastrophic. Philipov and Kohler (2001) provide several examples, an extreme one being the search for impeachment of Russia's ex-president Yeltzin, accused among other things in population genocide with one item being the fall in the birth rates.

Although this view to reasoning the fertility drop is widely shared, it has received surprisingly little scientific support. Scientific publications are country-specific, descriptive, and discuss the above-mentioned correlation in broader terms. U.N.E.C.E. 
(2000) provides a useful study on the effect of the transition's economic hardship on fertility in Central and Eastern Europe. Using vital statistics data, the report reached a positive conclusion for the existence and significance of such an effect. Cornia and Paniccià $(1995,1996)$ provide other relevant studies.

The economic explanation of the reduction in fertility is based on the escalation in the direct costs of children as a consequence of the collapse in income. It is most relevant to the South-Eastern European and the ex-Soviet Union countries. In Poland, the Czech Republic, Hungary, and particularly in Slovenia, the economic adjustment developed without any or with low recession and a rise in the costs of children could be observed only for subgroups of the population, for example among the impoverished people.

Relative deprivation is a social and economic aspect that is supposed to have a significant impact on fertility behavior. Lesthaeghe in several of his papers (1998, for example) provides a discussion in the case of western European countries and in the context of relative cohorts. Relative deprivation acquired a different aspect in the CEE countries, namely a cross-sectional one. Many people did not experience a significant drop in their personal well-being but considered themselves economically deprived relative to others. For example, some people with higher education than others could feel deprived because they received lower income. Another example is provided by the disappointment in people who have expected a more significant improvement of their economic situation with the arrival of a more democratic regime. In general, relative deprivation would mean that people assess their income as low relatively to others or to their personal expectations, and hence view their economic situation as inconvenient for having a(nother) child. In a political context, Sztompka (1996) discusses relative deprivation "after revolutionary elation and unrealistic hopes" (p.37).

The impact of longer education on fertility in Western European countries has been widely studied. It the light of the economic versus the ideational approach it is considered as the result of ideational shifts. In the CEE countries extensive rise in education is the result of increased demand of human capital during the transition, as it was described in section 1. Hence it is considered here in its socio-economic aspect rather than as the result of ideational change.

U.N.E.C.E. (2000) indicates the importance of increase in education on postponement and level of fertility. The discussion on education in the first section revealed that there is a significant rise in the enrolment ratio and in the length of education in the CEE countries. A higher level of education is likely to enforce an individual's preference to a job career. Therefore an augmenting circle of women are expected to postpone family events including births. ${ }^{5}$ This aspect of the transition could be an important reason for the recent fertility drop. Given the structural change on the labor market and the increased demand of highly qualified professionals it can be expected that educational expansion and its catalytic effect on job commitment will keep fertility low for quite some time in the future, at least where young adults are considered.

Economic uncertainty is another aspect of the economic approach, whose relevance to the fall in fertility in Eastern Europe is of particular importance because of its significant rise during the transition. Rising uncertainty is especially pertinent to countries that did not experience a profound economic recession. Ranjan (1999) discusses the topic in the CEE countries, and Bhaumik and Nugent (2002) suggest a detailed study in the case of Eastern Germany. 
Lack of housing has been a traditional reason for a preference to a low family size in the CEE countries. Its significance has increased during the recent decade, due to the lower income of people who therefore cannot afford buying a dwelling. Fratczak (2000, p.32) indicates the need of housing and its impact on fertility in Poland.

Deteriorating economic situation, education expansion, expensive housing, and rising economic uncertainty were discussed here as causes for the drop in fertility. It is likely that couples placed under the pressure of any of these factors will take a decision to postpone fundamental life events, such as a birth. Hence the explanation of the fertility trends discussed in the previous section may well rest on the economic approach.

\section{(b) The ideational approach}

This approach refers primarily to ideational changes, such as changes in norms, values, attitudes that cause consequential behavioral modifications. Aspects of culture like habits and traditions may have an impact on fertility change but will not be considered here because of the lack of information and relevant research.

The impact of ideational shifts on fertility behavior has been extensively studied where Western European and other developed societies are considered (Lesthaeghe 1983, Lesthaeghe and Van de Kaa 1986, Van de Kaa 1987, Hammel 1990, are among the first publications). These factors have a long-standing effect and develop for many decades and even centuries. Secularization, rising female autonomy, rising expressive individualism, are among the most relevant ones. They contribute to a lessening pressure of traditional norms pertaining to high fertility.

Lesthaeghe and Van de Kaa (1986) and Van de Kaa (1987) suggested the term "second demographic transition" to denote significant changes in demographic trends that occurred in Western Europe since the middle of the 60s. Where fertility is considered, these trends are like the ones described in the previous section, except that the speed of change was not as high. The authors emphasize the importance of ideational and particularly value changes for the explanation of these trends. The term gained large popularity among demographers in the CEE countries and particularly in the Central European countries. A recent book entitled "Demographic change in Poland during the 90 s in the light of the second demographic transition" provides a vivid example (Kotowska, 1999). The FFS SCR-s (see note1) provide country-specific discussions. The issue is often addressed in publications in the countries' population journals. There is a debate on the soundness of the approach though. Rychtaříková (2000) observes fertility changes as the result of crisis rather than of "intentional" change.

The impact of ideational changes on fertility decline in the CEE countries is discussed usually the way it is discussed for Western countries. Long-term secularization, rising individualism and female autonomy are seen as trends that have developed during the years of the totalitarian regime. The latter may only have hindered the fall in fertility through population policies. The start of the transition accelerated the ideational changes and the consequent fertility decline.

Studies on the second demographic transition in the CEE countries usually link it to the trends exhibited by vital statistics data. Since these trends are similar to those observed earlier in Western European countries, it is a straightforward analogy that the second demographic transition has been as effective in the eastern part of Europe as in its western part, although exhibited with some delay. 
The implementation of the "second demographic transition" approach to CEE countries is usually set in the framework of the overall changes in life and society. Thus it comprises more than just pure ideational changes. For example, the discussions evolve around female and young adults' labor force participation, conflicting roles of a working mother, rising education. As a consequence it interacts with the economic approach discussed above. Such an interaction is not surprising given the commonality between social, economic, and ideational change. Lesthaeghe (1998) discusses this topic from the theoretical viewpoint and his inferences serve as a theoretical justification of a similar approach.

\section{Economy or ideational shifts?}

The availability of two distinct explanatory approaches to the fertility drop raises a number of questions like the following ones. Which approach is the true one? Do they interact and how? Are the approaches valid for distinct sub-populations or both refer to the same individuals at the same time?

The search for an answer to similar questions encounters a significant problem, namely the lack of data. Research directed towards verification of the approaches is based on aggregate demographic data that describe general trends like those discussed above. It comes out that each one of the two basic theoretical approaches finds support in one and the same kind of data. Such a result indicates that data are insufficient. No country in the region disposes with panel fertility surveys. The FFS are the only ones available in the region. ${ }^{6}$ The FFS data have been used by researchers in the countries where they are available for the purpose to enrich the knowledge on demographic behavior and less so for its explanation. ${ }^{7}$

Hence the lack of adequate data hinders finding an answer to the question posed in the title of this section. Beside the data problems the traditional formulation of the economic approaches need additional clarification.

Consider the economic approach. It is based mainly on the impact of rising costs of children (direct costs in particular), as well as rise in relative deprivation and economic uncertainty. These economic aspects differ among countries and among sub-population groups within a country, specified by geographical regions for example. In addition, some people experienced a significant improvement of their economic situation. According to the economic approach it can be conjectured that fertility should be higher in countries or country regions where the economic crisis is less pronounced, and that the people that are better-off would have higher fertility. No indication of the validity of any one of these conjectures has become known by now.

Consider the ideational approach. How did ideational shifts rise overnight? Changes in norms and values are long-standing and must have started their development well before the start of the transition period. Then one may ask how could modern value orientations develop in a suppressive regime like the totalitarian one. The regime favored the rise in conformism and alienation, rather than in individualism and autonomy. Some modern values, such as female autonomy and secularization, were indeed widely spread over the region. The reason is in that they were imposed to the people. Female autonomy rose due to the significant increase in the share of working women. This increase was a 
consequence of the constitutionally guaranteed right of labor and the availability of working places. Hence female (economic) autonomy was a status achieved through the specifics of the regime, rather than through changes in values. The regime imposed restrictions on practicing religion. Although one may suppose that religiousness remained an internal value, unshared to others for the fear of sanctions, norms based on religion gradually weakened. Thus the regime contributed to the development of secularization.

Therefore both the economic and the ideational approaches bear significant drawbacks where the application of their conventional formulation is considered.

\section{The transition as a period of discontinuity, disorderliness and anomie}

The previous section demonstrates that evidences for the validity of the economic or the ideational approaches are sparse. While the lack of adequate data is one important reason for this observation, another one is connected to their argumentation. In this section I discuss aspects of the latter. The discussion here starts from the comprehension of the transition period as one of a social crisis.

The first section depicted discontinuity as a major characteristic of the transition period. It is manifested through the reconstruction in political, social, economic, and civil structural organizations and institutions from totalitarian to democratic ones. The old institutions are entirely reorganized or even demolished and new ones are being constructed. The abolition of the old is a momentous event, while the construction of the new is not. The new institutions emerge in an environment that is not perfect for their functioning, nor are they constructed free of errors. Their perfection thus may need a long time. Discontinuity refers to this time period, when the old institutions do not exist and the newer ones are still too weak for their regular functioning.

Kozul-Wright and Rayment (1997) studied economic aspects of discontinuity, terming the latter as hiatus. Hiatus existed in all spheres of society. Consider for example the legal system. The transition required changes in hundreds of laws. An enormous change of this magnitude requires a long period of time. New laws are often imperfect and need further amendments. Thus diverse niches in life experience the impact of lawlessness. Such a state of legal anomie has been described by Sztompka (1996, p.55): "The legal system is a fragmented mozaic of partial regulations, old and new, often inconsistent, repeatedly changed, arbitrarily interpreted...The rule of law is compromised by extra-legal decisions taken by the highest authorities...including retroactive legislation.. by the parliament. Trust in continuity, stability and the orderliness of social life is effectively undermined." This description was relevant at the time to nearly all, if not all, countries in the region.

Discontinuity refers to the period of time that starts with the destruction of the totalitarian society and is expected to end with the construction of a functioning democratic one. Discontinuity is the essence of the transition.

Discontinuity is pronounced in ideational shifts as well. The sudden overthrow of a totalitarian ideology brings about breaks in traditions, norms, and values. From the point of view of ideational shifts it represents a relatively short period of time when previously existing norms and values are broken and newer ones have still not settled. 
This is a state of deinstitutionalization and normative deregulation, known as social anomie (normlessness), following Durkheim's tradition in sociology. It has been the subject of research among social scientists in CEE countries during the 90s. Genov (1998) studied the impact of anomie on quality of life in Bulgaria. Using survey results he found high levels of reported uncertainty, anxiety, and fears. He classified the latter as telling an anomic situation. Rousselet (1994) discussed the lack of identity of the Russian society in the context of anomie, and the role that religion could play in the search for identity. Arts, Hermkens, and Van Wijck (1995) viewed disorderliness in the CEE countries in the light of the theory of anomie. The Czech journal "Sociologický ćasopis" devoted one of its issues to the topic of societal transformation as social anomie (Buriánek, 1994). Rabušic and Mareš (1996) used Srole's (1956) index of anomie to find from two independent surveys that while in November 1994, 29\% of the studied population was anomic, in June 1995 this share rose to 36\%. They found also that anomie increased with age and decreased with education. Their conclusion is that the longer the time period since the "velvet" revolution of 1989, the less enthusiasm the people have with respect to the transformation of society. Sztompka (1996) viewed social disruption as the "deficiency of cultural resources, the central of which is trust". "Widespread anomie" and "relative deprivation" have brought about the spread of a "culture of distrust". Detailed studies of anomie have been done in Hungary. The Hungarian household panel survey includes a battery of questions on anomie and related subjects such as alienation. although the battery has been changing it has been established that during the 90s there has existed a considerable anomie among the Hungarian people (Spéder et al. 1999; Andorka 1999).

Arts, Hermkens and Van Wijck (1995) base their analysis on the Durkheimian theoretical framework of anomie. In their words, "anomie... is a particular form of deinstitutionalization, ... a sudden normative deregulation of society... ... a particular form of individual disorientation. In a situation of anomie people are thrown back upon their own elementary behavioral propensities. This is due to the absence of a stable, external frame of reference which can restrain their needs and desires." (p. 2). Individual disorientation arises when "individual attitudes and actions have been disconnected from shared values, norms and behavioral standards" (p.3). The breakdown of societal rules brings about social disruption. "Uncertainty will increase because people no longer know what is still feasible or not, or what is or is not just, or what demands and desires cannot be justified." (p.3).

Discontinuity, anomie, or disorderliness are not specific to the CEE countries only. They have been a subject of discussion in the broader context of development (see for example Goulet, 1992).

This section described the transition as a time of disorderliness, discontinuity, anomie, disorientation. One can add to this list other relevant terms, such as alienation and dissatisfaction. Psychological items such as worry and depression are also relevant. I further use the term "discontinuity" that is seemingly the most general one. 


\section{Discontinuity and fertility}

The impact of discontinuity on the abrupt fall in fertility in the CEE countries has not been studied in the demographic literature, although some authors have discussed it in general terms. Nauck and Joos (1995) for example, briefly point to the primary importance of "unstable expectations for the future and shifts in life orientation" for the explanation of the abrupt fall of fertility in the former GDR but their indications seems not to have evolved further.

The link between discontinuity and fertility is not directly evident. It becomes more transparent when viewed through the prisms of the economic and particularly the ideational approaches to the study of fertility.

Consider first the economic approach. Discontinuity has an impact on fertility through the high level of uncertainty in life and insecurity of jobs and income. As it was discussed in the previous section, under the pressure of uncertainty, people are likely to postpone irreversible events such as births. Some individuals will postpone till complete rejection. Uncertainty thus causes postponement of births and fall in fertility. Uncertainty effects in a similar way marriage: people may prefer the less risky state of cohabitation that is not subject to a legal bond like marriage. Extra-marital fertility may rise in such non-marital unions.

Consider now the ideational approach. Firstly, the sudden weakening of normative regulations and restrictions opens the way to a wide range of changes in demographic behavior, including such that is typical for the second demographic transition: increase in extra-marital unions, postponement of marriage and births, rise in extra-marital fertility, decrease in births. Secondly, people that pertain to common values and norms will feel disoriented under conditions of anomie. For example, such people may have chosen a family formation through marriage and pertain to the two-child norm that prevailed until the start of the transition. Instead, being disoriented by the lack of a norm, they may feel uncertain in the decision taking regarding family size and timing and therefore postpone births. Analogously one can expect the spread of other forms of new demographic behavior. Thus demographic changes and value changes develop in parallel.

Ideational changes observed during the 90-s in the CEE countries differ from the long-standing ideational shifts towards a modern society observed in the western countries. The latter develop smoothly through the diffusion of new behavior. The way the former developed is a topic that remains to be studied.

The loss of desire to have a child is another important impact of anomie on fertility. It comes through Srole's measurement of anomie that rests on a scale constructed on several survey questions. One of them asks about agreement with the statement: "It is hardly fair to bring children into this world with the way things look for the future." (Srole, 1956). This paper will not consider the topic of measuring the impact of anomie on fertility; it is just indicative from Srole's scale that anomic people may have less desire for children.

Discontinuity does not distress to the same extent all the people in a population. Rabušic and Mareš (1996) discuss eunomie and semi-anomie as denoting weaker states of anomie. As mentioned above, they identified different groups of the population according to the level of anomie. 
Hence discontinuity is expected to exercise a negative impact on fertility. A theoretical framework of the links between fertility and discontinuity needs to answer the following question: who are the people that have children under such conditions of life? The framework developed by now in this paper explains why fertility should decrease but does not explain why it is positive. There exist at least two theoretical expansions that address this problem where the economic and ideational approaches are considered. Friedman, Hechter and Kanazawa (1994) argue that having a child reduces uncertainty. Schoen et al. (1997) find that Americans want children because they want to increase their social capital. The topic of social capital and family demography is elaborated further by Astone et al. (1999).

This paper discusses uncertainty and social capital in a different perspective. It brings forward the following hypothesis: the higher the social capital that an individual can raise, the lower his or her uncertainty in life and therefore the less likely is a negative decision for childbearing. This link does not contradict to the theories raised by Friedman et al. (1994) and Schoen et al. (1997). They view decrease in uncertainty and raise in social capital correspondingly, as a consequence of a birth. In the framework considered here, lower uncertainty and higher social capital are preconditions for having a child.

People react differently to worsened economic situation, weakened state institutions, break of norms and values, and uncertainty in general. Some of them remain passive, others take up specific actions, or coping strategies. Examples of widely spread coping strategies are finding additional job (second and often a third work), emigration, increase in education, entrepreneurship. Other examples of coping strategies are theft, tax evasion, corruption and bribe. ${ }^{8}$ Individuals that develop successful coping strategies ease the economic pressure on themselves and their families. They may feel less uncertain about the future. Therefore successful coping strategies may weaken the impact of uncertainty and low income on fertility.

Discontinuity and deinstitutionalization decreased significantly the support that the state and the community could provide to the citizens. People cannot count on these institutions for the development of successful coping strategies. It is natural that under such conditions they will rely more on their social ties and networks. A person can receive through his or her social network a loan, information, or in general, help of any kind. The more the help one can receive, the higher the chances that the person will be able to develop successful coping strategies and that uncertainty will be relatively lower. Such a person is likely to have higher chances for a positive decision for having a child. Coping strategies can be developed and uncertainty is likely to decrease even only when the person is aware that, were he or she in necessity, help could become available through the existing network and relationships. That is to say, the more the social resources a person can mobilize when necessary, the higher the chances for successful coping strategies, lower uncertainty, and therefore the higher the chances not to postpone or reject a birth. Mobilization of social resources refers to individual social capital. Hence higher social capital may lead to relatively higher fertility, and vice versa.

One has to maintain his or her social ties in order to rely on help whenever the need arises, i.e. to keep the individual social capital high. Ties require reciprocity in the relationship. In case one wants to be sure that help will be provided, one should be ready to provide help to others. Giving and getting help need not be viewed as an exchange between the same persons. They are two general links in the social network of the self. ${ }^{9}$ 
The concept of social capital is a topic of debates in social sciences (see for example Portes, 2000 and Lin, 2001). An important aspect of this discussion is whether it is an attribute to an individual or to a group, i.e. whether social capital is individual or collective. The latter can be at the level of relatives and friends, communities, cities, or a whole nation (Putnam 1993). Studies of social capital in CEE countries are scarce and the dimensionality aspect is not discussed in detail. Putnam (1993) and Fukuyama (1995) mention albeit briefly that the collective social capital in the CEE countries is low and this is an important reason for the lower level of well being of their populations. Nichols (1996) and Rose (1999) discuss the negative impact of the lack of social capital on the transition to a modern society in Russia.

Individual-level social capital has hardly been discussed in the context of the transition in the CEE countries. There is hardly any indication as to whether it has grown or decreased during the transition period. The context of the discussion in the preceding paragraphs suggests that a decrease in the individual social capital might be a cause for a decrease in fertility. This conjecture remains to be studied.

\section{Towards empirical evidence}

The theoretical approach described in the previous section implies that fertility change can be associated both to economic, social, and ideational factors, as well as to factors related to discontinuity and particularly anomie, individual social capital and coping strategies. There is no micro-level data set that could provide information on all these issues in a dynamic perspective. Two surveys supply partial information: the Russian Longitudinal Monitoring survey (RLMS) and the Fertility Survey that accompanied the 2001 Population census in Bulgaria. Round 8 of the RLMS from 1998 included for the first time questions on coping strategies that make possible the construction of variables related to individual social capital (Philipov and Shkolnikov, 2001) and therefore can only be used as a cross-sectional survey. The Bulgarian Fertility Survey (BFS) included similar variables. Neither survey includes variables explicitly related to discontinuity and anomie.

The data can be studied by using logistic regression with fertility intentions of women as the dependent variable. The two surveys have the following question: "Do you want to have (another) child)?". Binary answers to the question were used to supply observations of intentions. Schoen et al. (1997) used this modelling approach. They also discuss the adequacy of fertility intentions as a proxy variable of fertility. In Russia, fertility intentions are known to respond closely to observed fertility (see Andreev et al., 1998 for a recent discussion).

As it was shown in Section 2, the adjusted first-order TFR was high during the 90-s although lower than the level indicating universal birth of a child, with the exception that in Bulgaria its last available value in 1999 was around 0.90. Therefore it can be expected that the proportion of women wanting a first child can be very high, among cohabiting women in particular. For this purpose parity 0 is missed here. The data indicate that the proportion of women wanting to have a third or higher-order child is very small. For this purpose the focus of discussion here is on the intentions to have a second child. 
The explanatory variables are presented in three groups, outlined according to the basic approaches to fertility change: A: Social and economic, B: Cultural, and C: Social capital variables. The surveys do not contain variables that explicitly measure discontinuity or anomie. The selection of the variables was submitted to the idea to have as much the same variables for each country as possible. Table 7 gives the observed percentage distribution and the odds ratios for both countries.

The first group, social and economic variables, includes level of education and occupational status as social variables according to the scientific tradition in these countries. In studies of demographic change level of education is often considered as a cultural variable indicating ideational change. These two social variables have also an economic significance, insofar as human capital is a proxy for the level of income. Unemployed persons receive fixed-term benefits that are usually far below the subsistence level. The third variable in Russia measures family income, with individuallevel responses being aggregated into 3 groups. In Bulgaria, no variable measures income directly. Among possible substitutes preference was given to measurement of behavior than of subjective assessment of material situation. The selected binary variable is expected to demarcate low-level income: "Did you or your partner sell property to meet basic everyday necessities in the last two years?"

The second group of cultural variables includes settlement type and religiosity. Traditionally fertility is higher in rural areas and hence it can be expected that intentions for a second child should be higher. Urban and rural settlements maintain a traditionally significant difference in both countries with respect to norms and values; diffusion of new behavior runs in the direction from towns to villages. More religious persons are also expected to have higher fertility intentions. Measurement of religion is based on selfassessed belief in God in Russia and level of religiousness in Bulgaria. The number of siblings was additionally used in Bulgaria. The results are not reported because of the lack of comparison to Russia, although they were statistically significant. The selected variables reflect traditional aspects of culture; no variables were available that could reflect ideational changes such as increase in autonomy.

The third group comprises two variables referring to social capital. In line with the discussion above, getting help from relatives, friends, and others is a behavioral measure of raising resources embedded in social networks. Giving help is conceived as a measure of reciprocity that maintains the social ties and hence represents investment in social capital. A variable referring to coping strategies was used in the case of Russia. It is not included in table 7 because of the lack of statistical significance. This variable was constructed using information about starting a new job, working on own plot of land, pursuing increase in education, etc. Philipov and Shkolnikov (2001) give more details. They find it significant for the study of intentions for having a first child.

Age and marital status are not reported in table 7 but they have been considered in the estimations. Age effects were controlled using five-year age groups. The age span is 18-39 completed years.

The first block of variables reveals that the socio-economic status associates significantly with fertility intentions, thus supporting the economic approach to the fertility decline. Unexpectedly rise in education in Bulgaria increases significantly the intention to have a second child. Estimations of the author show that the data from the Bulgarian FFS disclose the same association between educational level and intentions for 
a second child. Additional studies are necessary for the understanding of this association. Unemployed women are less likely to intend a second birth than the employed. The growth of income associates positively with fertility intentions.

The second block shows that type of settlement is insignificant, but in Russia the odd ratio changes towards the expected direction. Lower religiosity links to lower intentions for a second child, although statistical significance was achieved in Bulgaria only.

The two variables in the group of variables representing social capital are statistically significant. This supports the theoretical approach presented in the previous section. During the times of discontinuity people rely on social capital and it is an important precondition in the formation of decisions about births.

The two variables referring to Bulgaria are highly correlated (correlation coefficient equal to 0.48). Skipping either one from the model would increase the statistical significance of the other one to make it the most significant in the whole variable set $(\mathrm{p}=0.0003)$, while the odds ratios for the other variables change only slightly. The same was observed when the two variables were factored into one (table 7). The correlation is not surprising in the light of the discussion in the previous section; it is the result of reciprocity in social relations, provided measurement of giving and receiving help is one and the same. The corresponding two variables in the Russian data are defined for different periods of time (help received during the last year, and help give during the last 30 days) and objects (help received by the respondent, help being given by any family member). Hence they measure different levels of giving and getting help and the correlation between them is very low.

Table 7: Variables and logistic regression results, Bulgaria 2001 and Russia 1998

\begin{tabular}{|c|c|c|c|c|}
\hline & \multicolumn{2}{|c|}{ Bulgaria } & \multicolumn{2}{|c|}{ Russia } \\
\hline variables and categories & $\begin{array}{l}\text { Observed } \\
\text { percentage } \\
\text { distribution } \\
(\mathrm{N}=815)\end{array}$ & $\begin{array}{c}\text { Odds } \\
\text { Ratios }\end{array}$ & $\begin{array}{l}\text { Observed } \\
\text { percentage } \\
\text { distribution } \\
(\mathrm{N}=659)\end{array}$ & $\begin{array}{c}\text { Odds } \\
\text { Ratios }\end{array}$ \\
\hline $\begin{array}{l}\text { Dependent variable } \\
\text {-Iintention to have another child } \\
\text { Does not want } \\
\text { Wants }\end{array}$ & $\begin{array}{l}42.0 \\
58.0 \\
\end{array}$ & & $\begin{array}{l}53.2 \\
46.8 \\
\end{array}$ & \\
\hline $\begin{array}{l}\text { A. Social and Economic characteristics: } \\
\text { - Achieved education } \\
\text { incomplete secondary } \\
\text { secondary and semi-higher } \\
\text { higher }\end{array}$ & $\begin{array}{c}9.4 \\
57.0 \\
33.6\end{array}$ & $\begin{array}{l}0.45 * * \\
1 \\
1.86 * *\end{array}$ & $\begin{array}{c}7.9 \\
73.2 \\
20.2\end{array}$ & $\begin{array}{l}1.22 \\
1 \\
1.13\end{array}$ \\
\hline $\begin{array}{l}\text { - Occupation } \\
\text { works } \\
\text { does not work } \\
\text { studies }\end{array}$ & $\begin{array}{c}64.6 \\
34.7 \\
1.2\end{array}$ & $\begin{array}{l}1 \\
0.68 * * \\
\text { small n.o. }\end{array}$ & $\begin{array}{c}57.2 \\
38.7 \\
4.1\end{array}$ & $\begin{array}{l}1 \\
0.74 \\
\text { small n.o. }\end{array}$ \\
\hline $\begin{array}{l}\text { - Family income (in Russia only) } \\
\text { Below } 750 \text { Roubles } \\
\text { Between } 750 \text { and } 1500 \text { Rbls } \\
\text { Above } 1500 \text { Roubles } \\
\text { - Sold property to satisfy basic needs (in } \\
\text { Bulgaria only) }\end{array}$ & $\begin{array}{l}- \\
-\end{array}$ & $\begin{array}{l}- \\
- \\
-\end{array}$ & $\begin{array}{l}28.9 \\
28.1 \\
43.0\end{array}$ & $\begin{array}{l}1 \\
1.65 * * * \\
1.96 * * *\end{array}$ \\
\hline
\end{tabular}




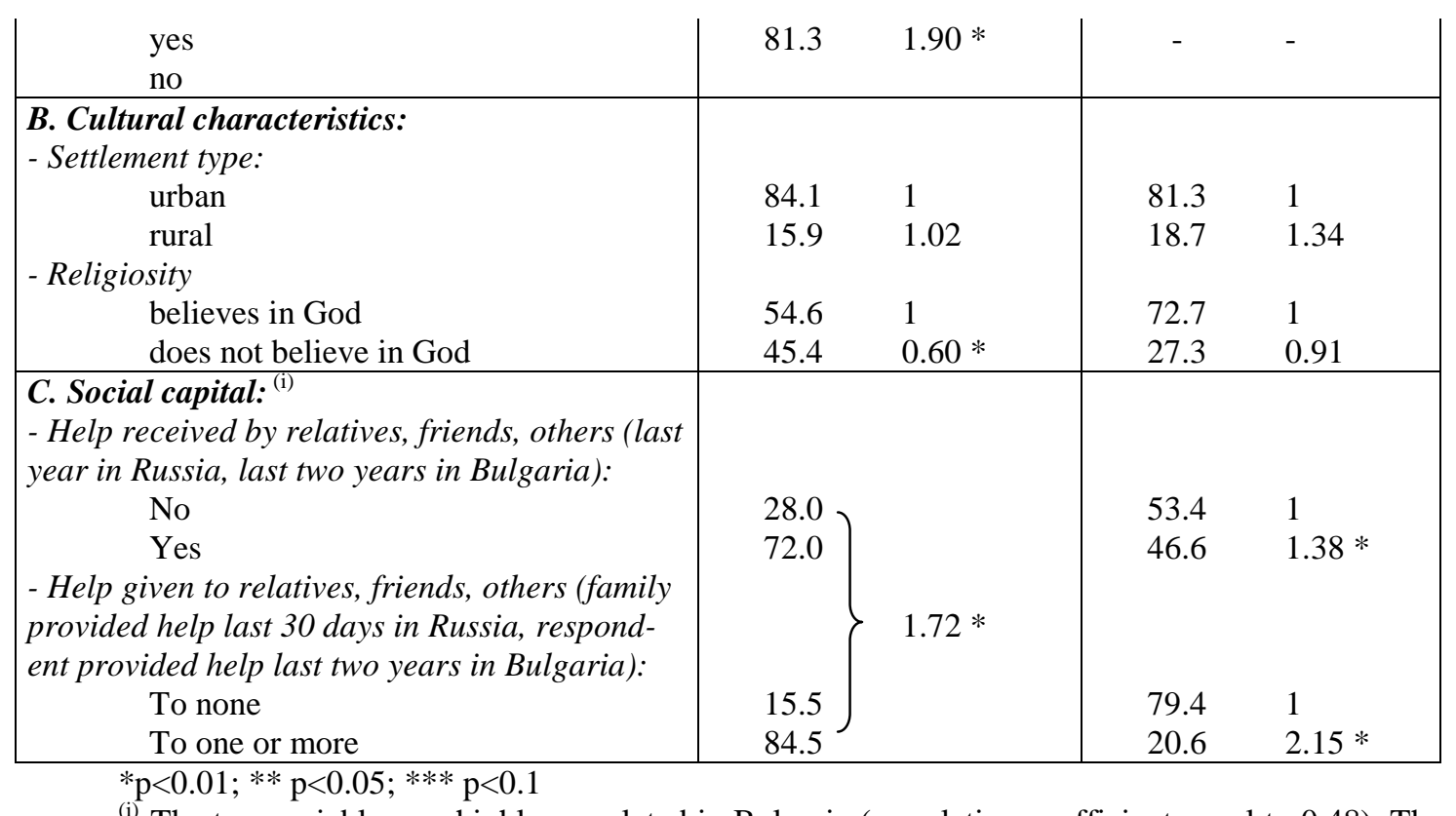

were factored into one, considered as continuous and growing with the growth of help. Its odds ratio i exhibited. Using instead each one of them separately would give equally high and statistically significant odds ratio without changing considerably the odd ratios for the other variables. See also the text.

Source: the data for Russia are taken from Philipov and Shkolnikov (2001).

This empirical search provides significant support to the importance of social capital in the formation of fertility intentions. The empirical findings restrict to the two countries only and their results cannot be superimposed on other countries. They reveal though that empirical studies in other countries would benefit from including social capital-related variables. It is particularly challenging to study the impact of social capital in the countries from Central Europe where the economic situation is considerably better than that in Bulgaria and Russia.

\section{Conclusion}

Economic hardship and ideational change dominate the explanations of the abrupt fertility fall in Central and Eastern Europe during the transition. Both approaches have been considered without taking into account the specific features of the overall changes in life. They need to encompass otherwise neglected fundamental characteristics of the transition, such as discontinuity, disorderliness, and anomie. The latter enforce the impact of economic hardship through increased insecurity of jobs and income, unemployment and impoverishment as well as through raised ineffectiveness of state, community and other support institutions.

Discontinuity and anomie create conditions for a sudden ideational change, different from diffusion or long-term development. The break of norms and disruption of values raise disorientation and thus obstruct the decision-making process with respect to family size. People prefer to avoid making decisions under conditions of uncertainty and thus postpone births and later perhaps rejecting them at all. 
Hence discontinuity and anomie connect the effect of economic and ideational factors on fertility. Economy and culture cannot be easily discerned. One of them may dominate in its impact on fertility, but the effect of the other one is present as well.

The impact of social disorderliness on demographic change has hardly been discussed in the demographic literature. Leasure (1992) discusses the start of the decline in marital fertility in Eastern Europe during the first half of the XX century raising a closely related hypothesis. He hypothesizes that the growth of autonomy was the main factor that caused political reforms and revolutions that accelerated the spread of new ideas and also increased control over one's reproductive life. The roots of growing autonomy are found in the XVIII Century Enlightenment and therefore his discussion refers to secular, long-term changes. In contemporary Eastern Europe, it is necessary to explain the suddenness of fertility change and this is where the study of discontinuity helps.

Discontinuity affects differently births of different order. Its effect is weak on decisions about first births, but considerably stronger for births of higher orders. Still the problem remains as to who are the people who give births of order higher than one, i.e. who are the people less effected by discontinuity.

Under conditions of discontinuity and societal deinstitutionalization a way to cope for an individual is to make use of the social capital accumulated in social ties and networks. Raising this capital may ease the burden of economic hardship and disorientation. A plausible way of measuring individual-level social capital is considering giving help to, or getting help from relatives, friends, neighbors, colleagues, and others. Giving and getting help need no be framed into exchange of help between the same persons. Survey data for Bulgaria and Russia support this conjecture.

The theoretical framework discussed here needs further evolvement into a rigid theory, or a set of theories. The availability of the latter would ease the search for empirical data and the choice of relevant models of analyses. The discussion in this paper and the presented empirical support serve as an initial step in this direction.

Finally, the discussion and the ideas will hardly apply with equal value to all the countries from the region. Discontinuity and anomie rise at different levels. This author conjectured in another paper (Philipov, 2001) that disorderliness in the countries from Central Europe is lower than in the Baltic countries, those in South-East Europe and the CIS countries; ideational change dominates in the former while economic change dominates in the latter.

Acknowledgement: the main ideas in this paper resulted from my joint work with Vladimir Shkolnikov. They were first exposed in a conference paper (Philipov and Shkolnikov 2001), in the context of Russia.

\section{NOTES}

\footnotetext{
${ }^{1}$ Fertility and Family Survey Country Report Series, issued by the Population Activities Unit at the Economic Commission for Europe, United Nations, Geneva. The following countries from Eastern Europe have carried out the FFS: Bulgaria, the Czech Republic, Estonia, Hungary, Latvia, Lithuania, Poland, and Slovenia.
} 
${ }^{2}$ At the start of the transition most of the countries experienced a quantum "shock", in that the quantum component dropped down dramatically in 2-3 years. The tempo effect was negligible and even negative (i.e. there was some advancement, not postponement, of births). Exceptions were Poland, Hungary, the Czech Republic, Slovenia.

${ }^{3}$ The level of infertility and particularly of secondary infertility has increased during the $90-\mathrm{s}$. See "O nekotorykh mediko-demograficheskikh I sotsial'nykh aspektakh razvitya podrostkov", Statisticheskoe obozrenie, 1999, N.3, where secondary infertility in Russia is cited at the level of 15-20\%. In Bulgaria it is as high as $16 \%$ (www.basrh.org).

${ }^{4}$ Note should be taken that these inferences are based on the validity of Bongaarts-Feeney formula. Kohler and Philipov (2001) and Ortega and Kohler (2002) discuss important extensions that allow for a more precise adjustment by eliminating structural effects in addition to the tempo effect. Their implementation is not likely to disprove the validity of the general inferences from above but may contribute to a deeper understanding of these important changes in fertility behavior. In addition, note is necessary that the adjusted TFR is a period measure of fertility. The interpretation of the drop in the adjusted TFR1 as a sign of voluntary childlessness derives from the expectation that its value is unrecoverable in a cohort perspective. union.

${ }_{5}^{5}$ Billari and Philipov (2002) discuss the interrelationship between education and entry into first

${ }^{6}$ Some statistical offices have conducted their surveys on fertility. They provide information that is unfortunately less relevant to the discussion here.

${ }^{7}$ The FFS data contain practically no information of the economic status of the respondents. Questions on values and norms refer to the time of survey and therefore cannot be used to study the impact of ideational shifts on fertility.

${ }^{8}$ An example of an economically passive coping strategy is working on own plot of land. The EBRD (2000), table 5.3, p.103, finds a high significance of subsistence informal work among ex-USSR countries and some countries situated in South-Eastern Europe.

${ }^{9}$ Reciprocity closely relates to trust: a value that is closely associated to social capital. The higher the trust, the higher the reciprocity and therefore the easier the flow of help among people. Hence it is easier to accumulate social capital. 


\section{References:}

Andreev, E., Bondarskaya, G., Har'kova, T. (1998): Fertility decline in Russia: hypotheses and facts. Voprosi Statistiki, 10. (In Russian)

Andorka R. (1999). Dissatisfaction and alienation. In: R. Andorka, T. Kolosi, R. Rose and G. Vukovich: A Society Transformed (Hungary in Time-Space Perspective). Central European University Press, Budapest (pp. 147-154).

Arts W., P. Hermkens, P. Van Wijck (1995). Anomie, distributive justice and dissatisfaction with material well-being in Eastern Europe. International Journal of comparative Studies, 36,1-2: 1-16.

Astone Nan Marie, C. Nathanson, R. Schoen, Y. Kim (1999). Family demography, social theory, and investment in social capital. Population and Development Review 25(1):1-31.

Bhaumik, S. and J. Nugent (2002). Does economic uncertainty have an impact on decision to bear children? Evidence from Eastern Germany. Paper presented at the Annual Meeting of the Population Association of America, Atlanta 2002.

Billari F. and D. Philipov (2002). Interrelationship between Education and Timing of First Unions: The Case of Central and Eastern Europe. Paper presented at the Annual Meeting of the Population Association of America, Atlanta 2002.

Blossfeld, H.-P. and Huinink, J. (1991). Human Capital Investments or Norms of Role Transition? How Women's Schooling and Career Affect the Process of Family Formation, American Journal of Sociology, 97/1, pp.143-168.

Bongaarts, J. and Feeney, G. (1998). On the Quantum and Tempo of Fertility. Population and Development Review 24:271-292.

Buriánek, Jiř́i (1994). The transformation as a social anomie - introduction. In: Sociologicky casopis; 30/2, pp.131-133 (in Czech)

Cornia, G. and R. Paniccià (1995). The demographic impact of sudden impoverishment:Eastern Europe during the 1989-94 transition. UNICEFF, Florence, Innocenti Occasional Papers EPS 49.

Cornia, G. and R. Paniccià (1995). The transition's population crisis: An econometric investigation of nuptiality, fertility and mortality in severely distressed economies. Most, N.1.

Council of Europe (2001): Recent Demographic Developments in Europe. Strasbourg.

David, H. (1999). From Abortion to Contraception. Greenwood Press.

Di Giulia P., R. Lesthaeghe, G. Moors, A. Pinelli (1999). Fertility tempo and quantum: an empirical test of major theories with data from four FFS-countries. IPD-Working Paper 2.

E.B.R.D. (1997; 2000; 2001) “Transition Report”. European Bank for Reconstruction and Development. 
Ellman M. (2000). The social costs and consequences of the transformation process. Papers from the ECE Spring Seminar, 2000. ECE, United Nations, Geneva.

Fratczak E. (2000). Changes in fertility pattern in Poland during the transformation period. Polish Population Review, 16.

Friedman Debra, M. Hehcter and S. Kanazawa (1994). A theory of the value of children. Demography 31: 375-401.

Fukuyama, Francis (1995). Trust: The Social Virtues and the Creation of Prosperity. New York: Free Press.

Genov, N. (1998). Transformation and anomie: problems of quality of life in Bulgaria. Social Indicators Research 43: 197-209.

Goulet, D. (1992). Development: creator and destroyer of values, World Development, Vol. 20, issue 3, p.467-475.

Hammel, E. (1990). A theory of culture for demography, Population and Development Review 16/3: 455-485.

Kohler, H.-P. and D. Philipov (2001). Variance effects in the Bongaarts-Feeney formula. Demography, 38/1, 1-16.

Kotowska, E. (2000). Demographic change in Poland during the 90s in the light of the second demographic transition (in Polish). Szkola Glowna Handlowa w Warszawie.

Kozul-Wright, R. and P. Rayment (1997). "The institutional hiatus in economies in transition and its policy consequences", Cambridge Journal of Economics, Vol. 21, N. 5, pp. 641-661.

Kučera, T., Kučerová, O. Opara, E. Schaich (2000). New demographic faces of Europe. Springer.

Kulczycki A. (1995). Abortion Policy in Post-communist Poland. Population and Development Review, 21(3).

Lesthaeghe, R. (1983). A century of demographic and cultural change in Western Europe: an exploration of underlying dimensions. Population and Development Review, 9/3, 411-434.

Lesthaeghe, R. (1998). On theory development and applications to the study of family formation. Population and development review, 24/1:1-14.

Lesthaeghe R. and D. van de Kaa (1986). "Twee demografische transities", in Lesthaeghe and van de Kaa (eds.) Bevolking, groei en krimp. Deventer: Van Loghum Salerus, 19-68.

Lesthaeghe, R. and G. Moors (1996). Living arrangements, socio-economic position, and values among young adults: a pattern description for France, West Germany, Belgium, and the Netherlands, in D. Coleman (ed.): Europe's population in the 1990s. Oxford University Press.

Lin, Nan (2001). Social Capital (A Theory of Social Structure and Action). Cambridge University Press. 
Milanovic B. (1998). Income, inequality and poverty during the transition from planned to market economy, World Bank, Washington D.C.

Monnier, A. (1996). The demographic impact of the transition in Central and Eastern European countries. Courrier des Pays de l'Est, 409, pp.74-91.

Monnier, A. and J. Rychtaříková (1992). The Division of Europe into East and West. Population: An English Selection. 4: 129-160.

Nauck, B. and Joos, M. (1995). East Joins West: Child Welfare and Market Reforms in the Special Case of the Former GDR. UNICEFF, Florence, Innocenti Occasional Papers EPS 48.

Nichols, Thomas (1996). Russian democracy and social capital. Social Science Information, 35(4), pp.629-642.

Ortega J.-A. and Kohler, H.-P. (2002). Measuring Low Fertility: Rethinking Demographic Methods. Working Paper 2002-01, Max-Planck Institute for Demographic Analysis, Rostock.

Philipov, Dimiter (2001). Low Fertility in Central and Eastern Europe: Culture or Economy? Paper presented at the IUSSP Seminar on "International Perspectives on Low Fertility: trends, theories and policies", Tokyo, March 21-23, 2001.

Philipov, Dimiter and Hans-Peter Kohler (2001). Tempo effects in the fertility decline in Eastern Europe: evidence from Bulgaria, the Czech Republic, Hungary, Poland, and Russia, European Journal of Population.

Philipov, Dimiter and V. Shkolnikov (2001). Fertility intentions and social capital-based coping strategies: results from the Russian longitudinal monitoring survey. Paper presented at the PAA meeting, Washington D.C 2001.

Portes, Alejandro (2000). The Two Meanings of Social Capital. Sociological Forum, Vol. 15, No.1, pp.1-12.

Putnam, Robert (1993). The Prosperous Community: Social Capital and Public Life. American Prospect 13: 35-42.

Ranjan, Priya (1999). Fertility Behaviour under Income Uncertainty, European Journal of Population, 15, pp.25-43.

Rabušic, L. and P. Mareš (1996). Is Czech Society Anomic? Sociologický časopis, XXXII:2, 175-187 (in Czech).

Rose, Richard (1999). Getting things done in an antimodern society: social capital networks in Russia. In: P. Dasgupta and I. Serageldin: Social Capital (A Multifacetted Perspective). The World Bank, Washington D.C., pp.147-171.

Rousselet K. (1994). Anomie, recherche identitaire et religion en Russie. Social compass 41/1, 137-150.

Rychtaříková, J. (1999). Is Eastern Europe experiencing a Second Demographic Transition? Acta Universitatis Carolinae, Geographica, N.1, pp19-44.

Schoen R., Kim Y., Nathanson C., Fields J., Astone N.M. (1997). Why do Americans want children? Population and Development Review. 23/2. 
Spéder Zsolt, B. Paksi, Zs. Elekes (1999). Anomie and Satisfaction at the Beginning of the Nineties. In: T. Kolosi, I. Tóth and G. Vukovich (editors): Social Report 1998; Social Research Informatics Center, Budapest; pp.483-505.

Srole, Leo (1956). Social integration and certain corollaries: an exploratory study. American sociological review 6, pp.709-716.

Sztompka P. (1996). Trust and emerging democracy. International sociology, 11(1):3762.

U.N.E.C.E. (1999). Fertility decline in the transition economies, 1982-1997: political, economic and social factors. Chapter 4 in: Economic Survey in Europe, 1999/1, pp. 181-194, United Nations Economic Commission for Europe, Geneva.

U.N.E.C.E. (2000). Fertility decline in the transition economies, 1989-1998: economic and social factors revisited. Chapter 6 in: Economic Survey in Europe, 2000/1, pp. 189-207, United Nations Economic Commission for Europe, Geneva.

van de Kaa D. (1987). Europe's second demographic transition. Population Bulletin 42,1.

van de Kaa D. (1998). Postmodern fertility preferences: from changing value orientation to new behavior. Séminaire "Démodinamiques", INED.

Vikat, Andres (1994) Family Formation in Estonia. Finnish Demographic Society, Helsinki.

W.I.I.W. (2000) Countries in Transition, 2000: Wiener Institut für Internationale Wirtschaftsvergleiche, Wien, table 5/2. 